\title{
Immunobiological relationships among new cholera toxins produced by CT gene-negative strains of Vibrio cholerae 01
}

\author{
SETARUNNAHAR SAHA and S. C. SANYAL*
}

Department of Microbiology, Institute of Medical Sciences, Banaras Hindu University, Varanasi, 221 005, India

\begin{abstract}
Summary. The enterotoxic activities of partially purified new cholera toxins (NCT) prepared from the CT gene-negative strains of Vibrio cholerae serotype $\mathrm{O} 1$ isolated from cases of diarrhoea in man and from diverse environmental sources were assayed in the rabbit ileal-loop model and the toxin unit was calculated in $\mu \mathrm{g}$ of protein content. The secretory activities of one unit of homologous and heterologous enterotoxins were completely neutralised by 2.5 units of crude antiserum raised against one NCT preparation. In immunodiffusion tests, the NCT preparations from all strains tested gave precipitin bands against one antiserum showing reaction of complete identity. Thus, the present study clearly demonstrated that NCTs elaborated by $\mathrm{CT}$ gene-negative strains of $V$. cholerae $\mathrm{Ol}$ are immunobiologically similar.
\end{abstract}

\section{Introduction}

A number of cholera toxin (CT) gene-negative strains of Vibrio cholerae of serotype $\mathrm{O} 1$ isolated from diverse environmental sources, from intestinal and extra-intestinal infection sites in man and from genetically engineered laboratory strains were used as candidates for live oral vaccines against cholera (Kaper and Levine, 1981; Levine et al., 1982; Mekalanos et al., 1982). These candidate vaccine strains caused diarrhoea in about one-third of the human volunteers to whom they were fed (Levine, 1986). We examined $13 \mathrm{CT}$ gene-negative $\left(\mathrm{CT}^{-}\right)$ strains in greater detail by a variety of enterotoxin assays to determine whether they lacked completely the ability to produce any toxin(s) and we reported earlier that these strains produced an enterotoxin which caused diarrhoea in infant rabbits, accumulation of fluid in ligated rabbit ileal loops and increased permeability in the skin of rabbits (Sanyal et al., 1983, 1984). This new cholera toxin (NCT) differs from CT in antigenic nature, receptor site, mode of action and genetic homology. Antisera against $C T$ and its $A$ and $B$ subunits did not neutralise the skin permeability-factor activity of NCT (Sanyal et al., 1984). Although it has been suggested that NCT is a Shiga-like toxin (SLT) (O’Brien et al., 1984; WHO Scientific Working Group, 1984) experimental data on these $\mathrm{CT}^{-}$

Received 26 May 1988; accepted 30 June 1988.

* Correspondence should be sent to Professor S. C. Sanyal. strains have not been presented. We, however, did not find any immunological relationship between NCT and Shiga-like toxin (S. C. Sanyal, unpublished data). Furthermore, NCT-producing, $\mathrm{CT}^{-}$ strains of $V$. cholerae did not hybridise with SLT 1 and SLT 2 probes indicating that they do not produce Shiga-like toxin (Dr P. Echeverria, personal communication).

Recently we reported that diarrhoeal isolates of CT gene-positive strains of $V$. cholerae $\mathrm{Ol}$ of Ogawa and Inaba types (including the kypertoxigenic strain 569B) also produce NCT (Sanyal et al., 1987; Saha and Sanyal, 1988). In the light of these observations, NCT has attained considerable significance in the pathogenesis of cholera. The present study was undertaken to measure the enterotoxic activity of partially purified NCT produced by $\mathrm{CT}^{-}$ strains of $V$. cholerae serotype $\mathrm{O} 1$ to establish whether antiserum against NCT of one strain neutralised the enterotoxic activities of homologous and heterologous strains in vivo, and to determine by gel diffusion the immunological relationships of NCTs produced by different $\mathrm{CT}^{-}$strains.

\section{Materials and methods}

\section{Bacterial strains}

The $\mathrm{CT}^{-}$strains $2740-80, \mathrm{X}-392,1074-78$ of $V$. cholerae serotype $\mathrm{O} 1$ were provided by Dr J. B. Kaper, Center for Vaccine Development, University of Maryland School 
of Medicine, Baltimore, USA; they had been isolated from cases of diarrhoea in man and from diverse environmental sources (see Sanyal et al., 1984).

\section{Preparation of crude enterotoxins}

Crude enterotoxins of the $\mathrm{CT}^{-}$strains of $V$. cholerae of serotype $\mathrm{Ol}$ were prepared in syncase medium (Finkelstein et al., 1966) by the method of Saha and Sanyal (1988). Thus, five or six smooth colonies from a pure overnight culture of a strain grown on nutrient agar were inoculated into each of $10(500 \mathrm{ml})$ conical flasks containing $100 \mathrm{ml}$ medium. The cultures were incubated at $37^{\circ} \mathrm{C}$ for $18 \mathrm{~h}$ with constant shaking (120 oscillations/ $\mathrm{min}$ ), centrifuged $(22000 \mathrm{~g}$ for $30 \mathrm{~min})$ at $4^{\circ} \mathrm{C}$ and the supernates passed through membrane filters $(0 \cdot 22-\mu \mathrm{m}$ average pore diameter; Millipore); filtrates were pooled and gradually saturated with recrystallised ammonium sulphate to $80 \%$ at $4^{\circ} \mathrm{C}$ with constant stirring. That suspension was held overnight at $4^{\circ} \mathrm{C}$, centrifuged $(22000 \mathrm{~g}$ for $30 \mathrm{~min})$ at $4^{\circ} \mathrm{C}$ and the precipitate was dissolved in $10 \mathrm{ml}$ of $0.04 \mathrm{M}$ phosphate-buffered saline (PBS), pH 7-2. Dialysis against 6-8 changes of the same buffer at $4^{\circ} \mathrm{C}$ for $36 \mathrm{~h}$ completely removed the ammonium sulphate. Dialysate was then passed through a membrane filter $(0.22 \mu \mathrm{m})$ and divided into small volumes for storage at $4^{\circ} \mathrm{C}$. This filtrate constituted the partially purified (crude) enterotoxin preparation, the protein content of which was estimated by the method of Lowry et al. (1951). Crude enterotoxins were similarly prepared from all strains used in the study.

\section{Preparation of antitoxin}

Albino rabbits (Belgian strain) weighing $2.5 \mathrm{~kg}$ were immunised by the method of Saha and Sanyal (1988) with crude enterotoxin prepared from the $\mathrm{CT}^{-}$strain X392 of $V$. cholerae 01 . Thus, $0.5 \mathrm{ml}$ of crude toxin $(0.32 \mathrm{mg}$ protein) in Freund's incomplete adjuvant was injected subcutaneously (s.c.); a further six doses ( $0.16 \mathrm{mg}$ protein) without adjuvant were given s.c. at 5-day intervals, and the rabbits were bled 5 days after the last injection. The crude, i.e., unabsorbed serum was used as anti-NCT serum. Serum collected from rabbits before immunisation served as negative-control serum.

\section{Assay of NCT}

The enterotoxic property of NCT was assayed by previously described methods (Burrows and Musteikis, 1966; Dubey and Sanyal, 1979). Graded doses of crude NCTs prepared from strains X-392, 2740-80 and 1074-78 were used as inocula and tested in the rabbit ileal-loop model (Sanyal et al., 1984). Experiments were done in triplicate for each dose of crude toxin tested and results were expressed as the average volume of fluid accumulated $/ \mathrm{cm}$ of gut in $8 \mathrm{~h}$. The amount of toxin (as protein) required to give a $50 \%$ reaction, equivalent to one unit of toxin (ED50), was calculated by interpolation of the dose- response curve of crude NCT plotted as the volume of fluid accumulated/cm of gut against the $\log _{10}$ toxin concentration. Crude enterotoxins of these strains and PBS, respectively, served as positive and negative controls.

\section{Neutralisation of NCT enterotoxic activity by anti- NCT}

Attempts were made to neutralise the enterotoxic activities of NCTs prepared from three $\mathrm{CT}^{-}$strains of $V$. cholerae $\mathrm{O} 1$ with antiserum prepared against NCT from strain X-392 in ligated ileal loops by previously described methods (Dubey and Sanyal, 1979; Lahíri et al., 1982). Aliquots ( $0.5 \mathrm{ml}$ ) of crude enterotoxin (containing $32 \mu \mathrm{g}$ protein and 1.33 units of toxin) were added to each of a series of doubling dilutions of antitoxin (to 1 in 512 ) in PBS, the mixtures were incubated in a water bath at $37^{\circ} \mathrm{C}$ for $30 \mathrm{~min}$ and tested thereafter in rabbit ileal loops to obtain the highest dilution of anti-NCT giving complete neutralisation of enterotoxic activities of NCT preparations (each of which had been adjusted to $64 \mu \mathrm{g}$ protein $/ \mathrm{ml}$ of PBS). Neutralisation coefficients for all dilutions of antitoxin were calculated by the method of Kasai and Burrows (1966). The volume of serum containing one unit of antitoxin and the amount of antitoxin required to neutralise one unit of toxin were calculated by interpolation of the $50 \%$ point in a logarithmic plot of neutralisation coefficient against volume of antiserum. An aliquot $(0.5 \mathrm{ml})$ of crude enterotoxins and pre-immunisation rabbit serum served as a positive control inoculum; PBS (1 ml) served as a negative control.

\section{Immunodiffusion tests}

Ouchterlony immunodiffusion tests were performed with NCT preparations from three $\mathrm{CT}^{-}$strains tested against anti-NCT prepared against strain X-392 to establish the antigenic relationships among these enterotoxins.

\section{Results}

\section{Titration of enterotoxic activity of NCTs}

Crude enterotoxin preparations from the $\mathrm{CT}^{-}$ strains of $V$. cholerae $\mathrm{Ol}$ gave optimum ileal-loop reactions at a protein content of $32 \mu \mathrm{g}$ and caused accumulation of $1.2 \mathrm{ml}$ of fluid/cm of rabbit gut. The toxin titration curve (fig. 1) showed that the upper asymptote was $1.2 \mathrm{ml} / \mathrm{cm}$ and the $50 \%$ effective dose (ED50) was $0.60 \mathrm{ml} / \mathrm{cm}$ of rabbit gut; that corresponded to one unit of toxin activity which contained $24 \mu \mathrm{g}$ of protein and the total crude enterotoxin preparation contained 13.33 units of toxin $/ \mathrm{ml}$. 


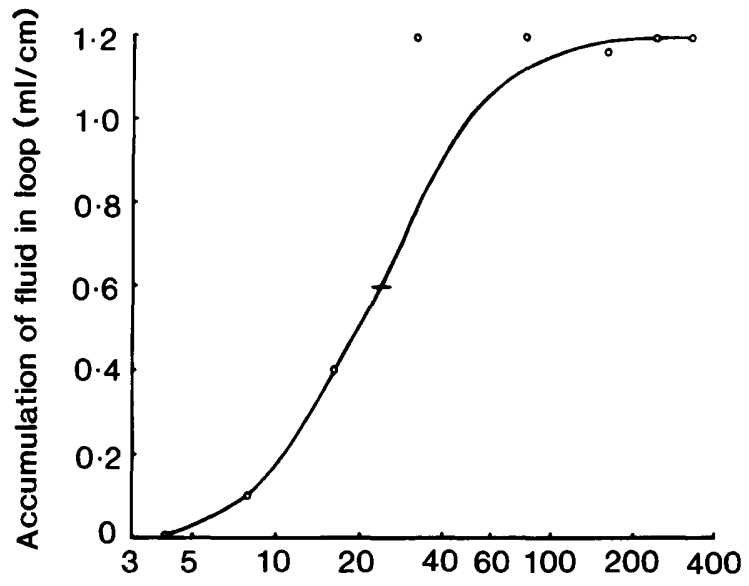

Enterotoxin ( $\mu$ g protein)/loop

Fig. 1. Dose-response curve of NCT preparation from CT strain $\mathrm{X}-392$ of $V$. cholerae $\mathrm{O} 1$; bar $=\operatorname{ED} 50(24 \mu \mathrm{g})$.

\section{Neutralisation of NCT enterotoxic activity}

The highest dilution of anti-NCT serum that completely neutralised the enterotoxic activities of NCTs prepared from different $\mathrm{CT}^{-}$strains of $V$. cholerae $\mathrm{O} 1$ in rabbit ileal loop was 1 in 32 and neutralisation was not observed when NCT toxin was mixed with normal pre-immunisation serum (fig. 2). There was proportionately less neutralisation of enterotoxin activity (i.e., more fluid accu-

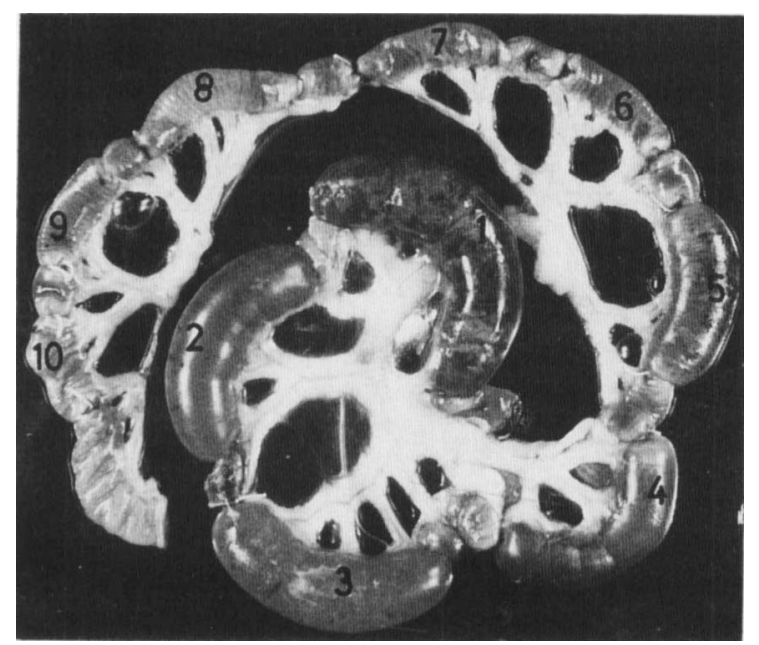

Fig. 2. Neutralisation of ileal loop-reacting activity of NCT by anti-NCT. Loop 1: positive control, $0.5 \mathrm{ml}$ of crude NCT mixed with $0.5 \mathrm{ml}$ of normal (pre-immunisation rabbit serum). Loops 2-9: $0.5 \mathrm{ml}$ of crude NCT mixed with $0.5 \mathrm{ml}$ of 1 in 512,1 in 256,1 in 128,1 in 64,1 in 32,1 in 16,1 in 8 and 1 in 4 dilutions of anti-NCT, respectively. Loop 10: negative control, $1.0 \mathrm{ml}$ of PBS. mulation) with higher serial dilutions of antitoxin. By interpolation of the $50 \%$-point in the logarithmic plot of neutralisation coefficient against volume of antiserum (fig. 3), it was found that $44 \times 10^{-4} \mathrm{ml}$ of antiserum contained one unit of antitoxin (i.e., 227.2 units of antitoxin $/ \mathrm{ml}$ of antiserum). The points on the graph fitted a slightly curved line when $\log _{10}$ neutralisation coefficient of $0 \cdot 166-1 \cdot 0$ and the $50 \%$-neutralisation volume were calculated by interpolation. The results of neutralisation experiments with one toxin preparation (containing $320 \mu \mathrm{g}$ of protein $/ \mathrm{ml}$ ) against a pool of hyperimmune rabbit antiserum (fig. 3) showed that $32 \mu \mathrm{g}$ of crude enterotoxin could be neutralised by a 1 in 32 dilution (3.32 units) of antitoxin. The amount of antitoxin required to neutralise the $\operatorname{ED} 50$ (i.e., one unit of NCT) was calculated to be $2 \cdot 5$ units. Similar neutralisation patterns were obtained in experiments with NCT preparations from other strains.

\section{Immunodiffusion tests}

In immunodiffusion tests, the crude enterotoxin preparations from all $\mathrm{CT}^{-}$strains of $V$. cholerae $\mathrm{O} 1$ gave precipitin bands with anti-NCT serum made against strain X-392 and showed reactions of complete identity (fig. 4).

\section{Discussion}

The present study indicated that crude enterotoxin preparations from the $\mathrm{CT}^{-}$strains of $V$. cholerae $\mathrm{O} 1$ contained a non-dialysable protein which caused accumulation of fluid in rabbit ileal

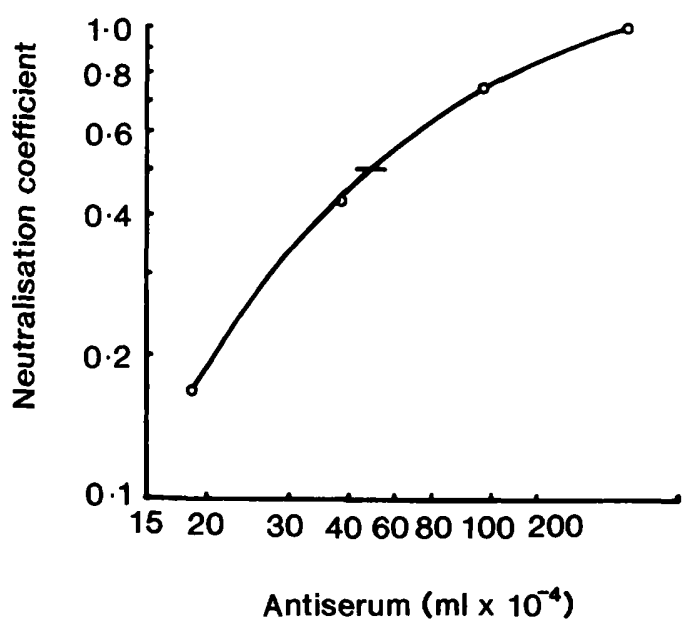

Fig. 3. Graph of the neutralisation coefficient $\left(\log _{10}\right)$ against antiserum concentration $\left(\log _{10} \times 10^{-4}\right)$ for interpolation of $50 \%$ neutralisation point. 


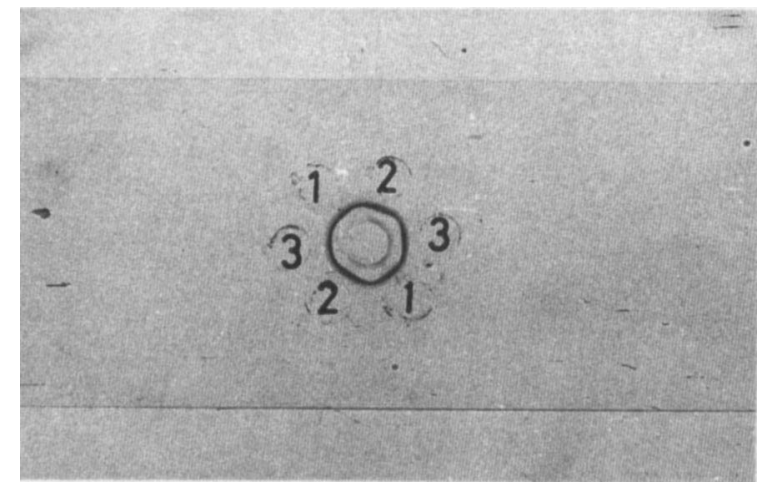

Fig. 4. Immunological identity of NCT preparations from CT strains of $V$. cholerae O1. Ouchterlony immunodiffusion analysis of NCT preparations from strains $2740-80$ (1), X-392 (2) and 1074-78 (3) against the antiserum of NCT prepared from strain X-392 (central well).

loops. Assay of partially purified NCT in ileal loops to measure its enterotoxic activity established that as little as $32 \mu \mathrm{g}$ of protein content caused a fullblown reaction indicating its significant secretory property. Furthermore, the finding that NCT, like CT, could be assayed in rabbit ileal loops, suggests some similarity in the secretory response to the two toxins.

NCT elicited an antibody response when inoculated into rabbits indicating that it was antigenic. The study also demonstrated that even very small amounts of crude anti-NCT serum against strain X-392 neutralised the enterotoxic activity of homologous and heterologous strains in ileal loops, an observation strongly suggestive of an immunobiological similarity of the NCTs produced by different $\mathrm{CT}^{-}$strains of $V$. cholerae $\mathrm{O} 1$. Moreover, the neutralisation of NCT by its antitoxin indicates that local antibody production in vivo may confer immunity to the secretory response of the NCT, as

\section{REFERENCES}

Burrows W, Musteikis G M 1966 Cholera infection and toxin in the rabbit ileal loop. Journal of Infectious Diseases 116: 183190.

Dubey R S, Sanyal S C 1979 Characterisation and neutralisation of Aeromonas hydrophila enterotoxin in the rabbit ileal-loop model. Journal of Medical Microbiology 12 : 347-354.

Finkelstein R A, Atthasampunna P, Chulasamya M, Charunmethee P 1966 Pathogenesis of experimental cholera: biologic activities of purified procholeragen A. Journal of Immunology 96 : 440-449.

Kaper J B, Levine M M 1981 Cloned cholera enterotoxin genes in the study and prevention of cholera. Lancet 2: 1162-63.

Kasai G J, Burrows W 1966 The titration of cholera toxin and has been shown for cholera. This property is of immense importance from the point of view of developing a live oral cholera vaccine and will necessitate a search for the presence of toxic and carrier subunits of NCT. Thus, like CT, the toxic moiety of NCT may be deleted by genetic manipulation so that the carrier portion, which should also be immunogenic, is retained and is able to elicit antibody response in the gut; in the absence of subunit structures, some other novel method may achieve complete protection against the disease.

In immunodiffusion tests, the crude enterotoxins of three $\mathrm{CT}^{-}$strains of $V$. cholerae $\mathrm{O} 1$ gave precipitin bands against antiserum raised against one of these preparations, showing complete reaction of identity. This observation confirms that the $\mathrm{CT}^{-} V$. cholerae $\mathrm{O} 1$ strains isolated from cases of human diarrhoea and from diverse environmental sources produce antigenically identical enterotoxins. It has been demonstrated previously that CT gene-positive diarrhoeal isolates of $V$. cholerae $\mathrm{O} 1$ also elaborate NCTs antigenically like that of the $\mathrm{CT}^{-}$strain X-392 (Saha and Sanyal, 1988). These data together indicate that NCTs produced by CT gene-positive or -negative strains of $V$. cholerae $\mathrm{O} 1$ of diverse origin are immunologically similar.

The present study clearly demonstrates that NCTs elaborated by the $\mathrm{CT}^{-}$strains of $V$. cholerae $\mathrm{Ol}$ are immunobiologically identical. Furthermore, CT gene-deletion mutant strains, obtained either from different sources or tailored in the laboratory, may cause a secretory effect in the gut of a susceptible host as a result of production of NCT. A candidate live oral cholera vaccine strain should, therefore, elicit immunity against NCT also.

We gratefully acknowledge the help of Dr R. K. Agarwal and $\mathrm{Mr}$ S. K. Saha at different stages of the work. antitoxin in the rabbit ileal loop. Journal of Infectious Diseases 116: 606-614.

Lahiri A, Agarwal R K, Sanyal S C 1982 Biological similarity of enterotoxins of Vibrio cholerae serotypes other than type 1 to cholera toxin and Escherichia coli heat-labile enterotoxin. Journal of Medical Microbiology 15: 429-440.

Levine M M et al. 1982 The pathogenicity of nonenterotoxigenic Vibrio cholerae serogroup O1 biotype El Tor isolated from sewage water in Brazil. Journal of Infectious Diseases 145: 296-299.

Levine M M 1986 Prospects for vaccines. The Magazine of the World Health Organization, April 24-26.

Lowry O H, Rosebrough N J, Farr A L, Randall R J 1951 Protein measurement with the Folin phenol reagent. Journal of Biological Chemistry 193: 265-272. 
Mekalanos J J, Moseley S L, Murphy J R, Falkow S 1982 Isolation of enterotoxin structural gene deletion mutations in Vibrio cholerae induced by two mutagenic vibriophages. Proceedings of National Academy of Sciences of the USA 79: $151-155$.

O'Brien A D, Chen M E, Holmes R K, Kaper J, Levine M M 1984 Environmental and human isolates of Vibrio cholerae and Vibrio parahaemolyticus produce a Shigella dysenterae 1 (Shiga)-like cytotoxin. Lancet $1: 77-78$.

Saha S, Sanyal S C 1988 Cholera toxin gene-positive Vibrio cholerae $\mathrm{O} 1$ Ogawa and Inaba strains produce the new cholera toxin (FEM 03161), FEMS Microbiology Letters 50: 113-116.
Sanyal S C, Neogi P K B, Alam K, Huq M I, Al-Mahmud K A 1983 A new cholera toxin. Lancet 1: 1337.

Sanyal S C, Alam K, Neogi P K B, Huq M I, Al Mahmud K A 1984 A new enterotoxin produced by Vibrio cholerae $\mathrm{Ol}$. Journal of Diarrhoeal Diseases and Research 2: 3-12.

Sanyal S C, Saha S, Saha S K, Ahsan C R 1987 Immunologic and genetic interrelationship between enterotoxins. In: Gopalakrishnakone P, Tan C K (eds) Progress in venom and toxin research. National University of Singapore, Singapore, pp 669-679.

World Health Organization 1984 Report of the Scientific Working Group on bacterial enteric infections; 12-14, September, 1984, Geneva. 